\title{
Extinction and food-reinforced inhibition of conditioned salivation in dogs
}

\author{
DENNIS L. HERENDEEN \\ Georgia Regional Hospital at Atlanta, P. O. Box 32407, Decatur, Georgia 30034
}

and

\author{
MARTIN M. SHAPIRO \\ Emory University, Atlanta, Georgia 30322
}

\begin{abstract}
The present experiment compared two methods of eliminating a classically conditioned response in dogs, extinction and reinforcement of nonsalivation, using both a within- and between-subjects experimental design. Eighteen dogs were trained for 16 days in Phase I, 16 days in Phase II, and 8 days in Phase III. In Phase I, each subject received classical conditioning training to two stimuli. In Phase II, Group 1 received extinction training to one stimulus and reinforcement of nonsalivation to the other stimulus. Group 2 received continued classical conditioning training to one stimulus and reinforcement on nonsalivation training to the other. Group 3 received continued classical conditioning training to one stimulus and extinction training to the other. In both the within- and between-subjects comparisons, responding to the stimulus associated with extinction was eliminated faster than responding to the stimulus associated with reinforcement of nonsalivation.
\end{abstract}

A classically conditioned response is extinguished if the conditioned stimulus which was previously paired with the unconditioned stimulus is presented alone. Although Sheffield (1965) unsuccessfully attempted to demonstrate an alternative procedure for eliminating a conditioned response through what he termed omission training, we have shown in an earlier paper (Shapiro and Herendeen, in press), using a within-subjects discrimination procedure, that classical conditioning may be overridden by a response dependency, specifically that salivation may be eliminated by imposing a response dependency in which the failure to emit a criterion response for a specified period of time was followed by food reinforcement. In this procedure, the reinforcing stimulus was withheld if the criterion response was emitted during the specified time period.

The purpose of the present experiment was to compare the relative effectiveness of reinforcement on nonresponding and extinction as methods for response elimination. Several experimenters employing an instrumental conditioning approach have attempted a comparison of extinction and a procedure similar to the reinforcement of nonsalivation procedure used in this experiment (Harman, 1973; Snow \& Uhl, 1968; Topping, Pickering, \& Jackson, 1971; Uhl \& Garcia, 1969; Uhl \& Sherman, 1971; Zeiler, 1970, 1971). The results from these experiments which compared the differential reinforcement of other behavior (DRO) with extinction have been inconsistent. A comparison between the two methods of response elimination has

This research was supported in part by Grant No. HD-0133 from the National Institute of Health to the second author. Part of these data were presented at the annual meeting of the Midwestern Psychological Association Convention in Cleveland Ohio, May 1972. not been attempted previously within a classical conditioning framework since no analogous methodology was available. The present experiment was designed to investigate extinction of salivation and reinforcement of nonsalivation in dogs using both a within- and between-subjects experimental design and to compare the effectiveness of the two procedures for response elimination utilizing a classical conditioning paradigm.

\section{METHOD}

\section{Subjects}

The subjects were 18 experimentally naive mongrel dogs obtained from the Emory University Animal Detention House. Each dog was housed in an individual cage with water, but not food, available at all times.

\section{Apparatus}

The experimental chambers were cubes, approximately $61 \mathrm{~cm}$ on a side. Each chamber contained houselights, ventilating fan, speaker, and a food tray. A Universal feeder delivered approximately $8 \mathrm{~g}$ of Wayne Bite Size dog food on each reinforced trial.

Each experimental chamber was located in a separate sound-attenuated room. Electro-mechanical programming and recording equipment, located in a nearby room, was used to present the stimuli to the animals and record their responses. The two auditory stimuli used in this experiment were a $1,600-\mathrm{Hz}$ tone and white noise, each approximately $80 \mathrm{~dB}$. The sessions, conducted with the chambers in complete darkness, consisted of 12 trials per day. The mean intertrial interval was $8.5 \mathrm{~min}$.

\section{Surgical Preparation}

The surgical procedure (see Shapiro \& Miller, 1965) consisted of inserting a marker tube into the orifice of Stensen's duct and blunt dissecting the duct through an external incision.

One end of a previously prepared U-shaped polyethylene tube was inserted into the duct, ligated, and sutured to the surrounding muscle. The other end of the tube was run 
Table 1

Experimental Design

\begin{tabular}{|c|c|c|c|}
\hline & $\begin{array}{l}\text { Phase } 1 \\
16 \text { Days }\end{array}$ & $\begin{array}{l}\text { Phase } 2 \\
16 \text { Days }\end{array}$ & $\begin{array}{l}\text { Phase } 3 \\
8 \text { Days }\end{array}$ \\
\hline Group 1 & $\begin{array}{l}S_{1} \ldots F \\
S_{2} \ldots F\end{array}$ & 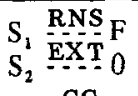 & $\begin{array}{l}S_{1} \cdots F \\
S_{2} \cdots F\end{array}$ \\
\hline Group 2 & $\begin{array}{l}S_{1} \ldots F \\
S_{2} \cdots F\end{array}$ & $\begin{array}{l}S_{1} \text { CC } F \\
S_{2} \text { RNS } F\end{array}$ & $\begin{array}{l}S_{1} \cdots F \\
S_{2} \cdots F\end{array}$ \\
\hline Group 3 & $\begin{array}{l}S_{1} \ldots F \\
S_{2} \ldots F\end{array}$ & $\begin{array}{l}S_{1} \mathrm{CC} F \\
S_{2} \mathrm{EXT}\end{array}$ & $\begin{array}{l}S_{1} \cdots F \\
S_{2} \cdots F\end{array}$ \\
\hline
\end{tabular}

Note- $S_{1}=$ Stimulus 1 (either tone or noise), $S_{2}=$ Stimulus 2 , $F=$ food, $0=$ no food, $R N S=$ reinforcement of nonsalivation, $E X T=$ extinction, $C C=$ classical conditioning, $\ldots=$. $=$ is followed by.

underneath the dog's skin and out a small incision on the dorsal surface of the dog's neck. The external incision in the cheek was then closed. If the preparation failed, the other duct was prepared and used for the remainder of the experiment.

\section{Recording System}

The salivary response was recorded by connecting the dog's tube to a second tube protected by a cable and run through the top of the experimental chamber. After passing through a hole in the top of the chamber, this second tube was connected to a specially prepared glass L-shaped tube, $.93 \mathrm{~cm}$ in diam, containing approximately $100 \mathrm{ml}$ of $90 \%$ water and $10 \%$ alcohol. The bottom of the glass tube was connected to a drop counting device located $1.5 \mathrm{~m}$ below the level of the chamber top. Each drop of saliva closed a gap between a 22-ga stainless steel hypodermic needle and a brass rod and activated a pulse former which operated electro-mechanical and printing counters.

\section{Procedure}

Three groups of six dogs each were trained for a total of 50 days. Ten days of magazine training were followed by 16 days of Phase I training. The dogs were prepared surgically between the 10 th and 11 th days of Phase I. During Phase I, each group of dogs received classical conditioning training with two stimuli. The order of trials on which each of the two conditioned stimuli were presented was unsystematic. Either a $1,600-\mathrm{Hz}$ tone or a white noise was presented for $10 \mathrm{sec}$ on each trial and was followed by $2 \mathrm{sec}$ of food presentation. The auditory stimulus and the food terminated simultaneously.

The three experimental groups differed with respect to the 16 days of Phase II training. For Group 1, six of the daily trials consisted of extinction to one stimulus with presentations of one auditory stimulus no longer followed by food; the other six trials consisted of reinforcement of nonsalivation in which the other auditory stimulus terminated with food if the dog salivated less than two drops. If the dog salivated two or more drops, the stimulus terminated at the end of $10 \mathrm{sec}$ without food. For Group 2, one-half of the trials were reinforced classical conditioning trials to one stimulus and one-half were reinforcement of nonsalivation trials with the other stimulus. For Group 3, one-half of the trials were reinforced classical conditioning trials to one stimulus and one-half were extinction trials with the other stimulus. Two drops were used as the response criterion for reinforcement of nonsalivation because partially formed drops result in an error of measurement of one drop.

For all groups, Phase III consisted of 8 days of six trials of reinforced classical conditioning with each of the auditory stimuli presented in an unsystematic order. Both stimuli were again followed by presentation of the food independent of the subject's behavior.
For all groups, tone and noise assignments were counterbalanced.

\section{RESULTS}

Analysis of variance indicated that the three groups of subjects responded indiscriminately to the two classically conditioned stimuli following surgical preparation in Phase I $(\mathrm{F}<1, \mathrm{df}=2,75)$.

The data require a somewhat more elaborate analysis in Phase II. Experimental procedures for eliminating responding produce many zero values and therefore create skewed distributions. This impediment to statistical analysis was overcome by computing a difference score between the number of responses under the two contingencies. More specifically, a difference score was obtained for each animal eac! day; these scores were then analyzed across days for each subject to yield an individual $t$ test for matched pairs. Since $t$ values are approximately normally distributed, the $t$ value for each subject was used in analyzing the data for the group as a whole. Group 1 subjects responded significantly more to the stimulus associated with reinforcement of nonsalivation than to the stimulus associated with extinction $(\mathrm{t}=4.32$, df $=15, \mathrm{p}<.01)$. Group 2 subjects responded significantly more to the classical conditioning stimulus than to the stimulus associated with reinforcement of nonsalivation $(t=2.94$, $d f=15, p<.05)$. Group 3 subjects responded significantly more to the classical conditioning stimulus than to the stimulus associated with extinction $(\mathrm{t}=8.07$, $\mathrm{df}=15, \mathrm{p}<.001)$.

Using the difference scores computed above, comparisons among groups were made by a 3 (groups) by 16 (sessions) analysis of variance. The groups were not significantly different $(F=2.95, d f=2,15, p>.05)$ but the Sessions effect and the Groups by Sessions

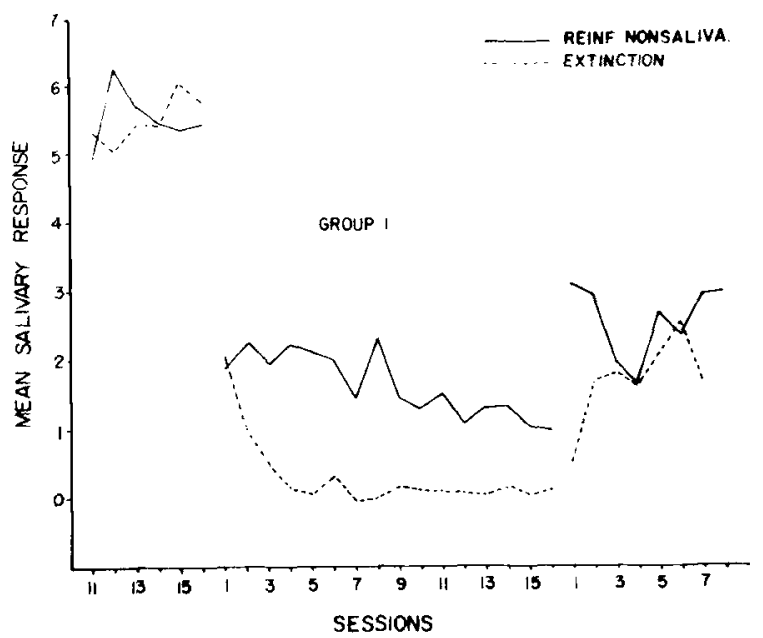

Figure 1. Mean salivary response for Group 1, Phases I-III, for both the extinction stimulus and the stimulus associated with reinforcement of nonsalivation. 


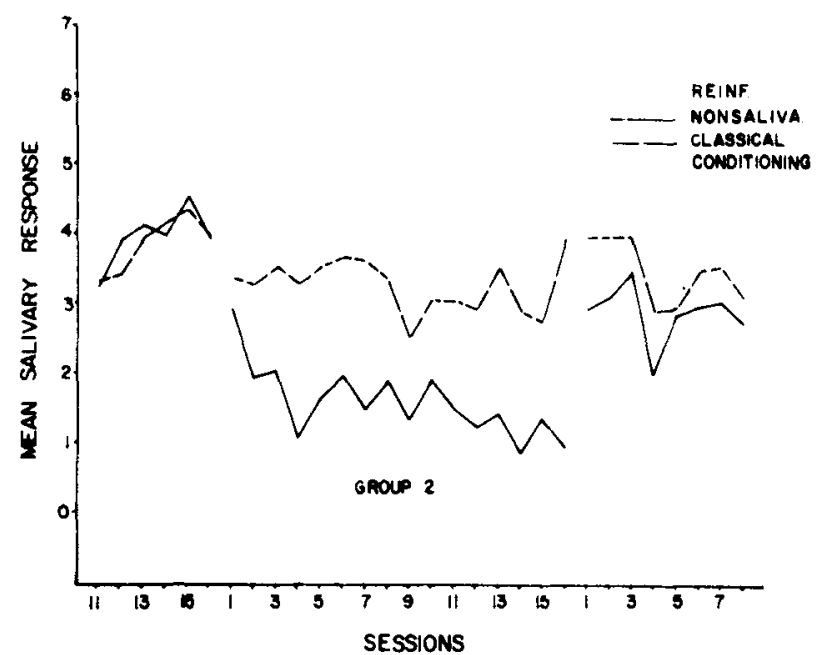

Figure 2. Mean salivary response for Group 2, Phases I-III, for both the classical conditioning stimulus and the stimulus associated with reinforcement of nonsalivation.

interaction were both significant $(\mathrm{F}=3.92, \mathrm{df}=15,225$, $\mathrm{p}<.01 ;$ and $\mathrm{F}=3.19, \mathrm{df}=30,225, \mathrm{p}<.01$, respectively).

This interaction was partitioned; responding in the group (Group 1) that received both extinction and reinforcement of nonsalivation was compared to the two groups (Groups 2 and 3 ) that had received either extinction or reinforcement of nonsalivation. The two groups that had received either extinction or reinforcement of nonsalivation in Phase II responded more than the group that received both extinction and reinforcement of nonsalivation $(\mathrm{F}=2.92$, $\mathrm{df}=15,225$, $\mathrm{p}<.01)$. The former two groups were also compared between themselves; the group that received reinforcement of nonsalivation and classical conditioning (Group 2) in Phase II was significantly different from the group that received extinction and classical conditioning (Group 3$)$ in Phase II $(F=3.44$, df 15,225 , $\mathrm{p}<.01$ ).

An analysis of variance of the reconditioning data from Phase III for Group 1 yielded a significant Stimulus by Sessions interaction which indicated that the difference between responding to the stimuli previously associated with the reinforcement of nonsalivation and extinction disappeared by the third day $(F=2.46$, $\mathrm{df}=7,28, \mathrm{p}<.05$ ).

The experimental procedures for Groups 2 and 3 included reinforced classical conditioning to one stimulus throughout all three phases of the experiment. There was no difference between the two groups in responding to that stimulus in Phase $I(F<1, d f=1,10)$. Group 3 responded more than Group 2 to that stimulus in Phase III $(F=7.51, \mathrm{df}=1,10, \mathrm{p}<.05)$. Group $3 \mathrm{had}$ a second stimulus associated with reinforcement of nonsalivation in Phase II.

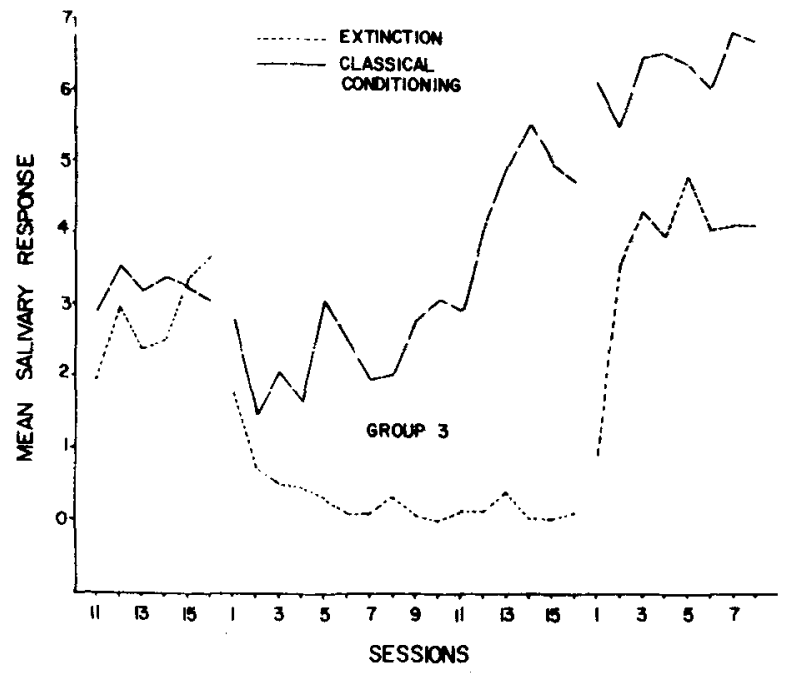

Figure 3. Mean salivary response for Group 3, Phases I-III, for both the classical conditioning stimulus and the extinction stimulus.

\section{DISCUSSION}

The present experiment, in conjunction with the previous experiment by Shapiro and Herendeen (in press), shows that dogs can inhibit a classically conditioned response when an appropriate response dependency is imposed.

A comparison of the present finding, that extinction is more effective than reinforcement of nonsalivation, with previous findings from experiments using instrumental learning procedures probably would be premature. The results of the present experiment taken alone, however, do support three important conclusions. First, the previous finding of Shapiro and Herendeen (in press), that inhibition of salivation may be obtained by the addition of a response dependency, was replicated. Classical conditioning may be overridden by an added response dependency. Second, reinforcement of nonsalivation not only reduced responding to a stimulus associated with the response dependency, but also attenuated responding to a stimulus associated with classical conditioning which had no response dependency. Some of the decreased responding to the stimulus associated with reinforcement of nonsalivation transferred to the classically conditioned stimulus. Third, responding to the extinction stimulus was eliminated faster than responding to the stimulus associated with reinforcement of nonsalivation in both the within- and between-subjects comparisons. Extinction of salivation was more effective in reducing responding than was reinforcement of nonsalivation.

It is often conjectured that classical conditioning involves stimulus substitution in which the conditioned stimulus becomes an effective substitute for the unconditioned stimulus. If this were true, it would not 
be surprising that inhibition of responding to the conditioned stimulus would be more difficult in the presence of the unconditioned stimulus and response than in the absence of the unconditioned stimulus and response. Response elimination would, therefore, be expected to be more efficient with extinction than with reinforcement of nonsalivation. The finding that reinforcement of nonsalivation inhibited responding to both the stimulus associated with this reinforcement dependency and another stimulus associated with classical conditioning also fits this conception. Both stimuli may be viewed as potentially substitute stimuli for the same unconditioned stimulus and, therefore, considerable generalization would be expected.

The finding that reinforcement of nonsalivation is a means of eliminating responding is supported by the results of this experiment. It is equally clear that the method is not as efficient as extinction and that the discrimination, although acquired by the dogs, is a difficult one with a great deal of generalization occurring between stimuli.

\section{REFERENCES}

Harman, R. E. Response elimination in concurrent and single operant situations with pigeons. Learning and Motivation, $1973,4,413-417$.
Shapiro, M. M., \& Herendeen, D. L. Food-reinforced inhibition of conditioned salivation in dogs. Journal of Comparative and Physiological Psychology, in press.

Shapiro, M. M., \& Miller, T. M. On the relationship between conditioned and discriminative stimuli and between instrumental and consumatory responses. In W. Prokasy (Ed.) Classical conditioning: $A$ symposium. New York: Appleton-Century-Crofts, 1965.

Sheffield, F. D. Relation between classical and instrumental learning. In W. Prokasy (Ed.), Classical conditioning: $A$ symposium. New York: Appleton-Century-Crofts, 1965.

Snow, M. E., \& Uhl, C. N. Effects of omission, extinction and changeover delay procedures on free operant discrimination performance. Communications in Behavioral Biology, 1968, 5 , No. 5.

Topping, J. S., Pickering, J. W., \& Jackson, J. A. The differential effects of omission and extinction following DRL pretraining. Psychonomic Science, 1971, 24, 137-138.

UhI, C. N., \& Garcia, E. E. Comparison of omission with extinction in response elimination in rats. Journal of Comparative and Physiological Psychology, 1969, 69, 554-562.

Uhl, C. N., \& Sherman, W. O. Comparison of combinations of omission, punishment, and extinction methods in response elimination in rats. Journal of Comparative and Physiological Psychology, 1971, 74, 59-65.

Zeiler, M. D. Other behavior: Consequences of reinforcing not responding. The Journal of Psychology, 1970, 74, 149-155.

Zeiler, M. D. Eliminating behavior with reinforcement. Journal of the Experimental Analysis of Behavior, 1971, 16, 401-405. 